\title{
Stay in the Game: Gender, Family Formation and Alternative Trajectories in the Academic Life Course
}

\author{
Nicholas H. Wolfinger, University of Utah \\ Mary Ann Mason, University of California, Berkeley \\ Marc Goulden, University of California, Berkeley
}

Academic careers have traditionally been conceptualized as pipelines, through which young scholars move seamlessly from graduate school to tenure-track positions. This model often fails to capture the experiences of female Ph.D. recipients, who become tenure-track assistant professors at lower rates than do their male counterparts. What do these women do instead? We use panel data from the 1983-1995 Surveys of Doctorate Recipients to explore the early careers of Ph.D. recipients. Our results show that female doctorate recipients are disproportionately likely to be employed as adjunct faculty or exit the paid labor force, especially if they have young children. Contrary to conventional wisdom, adjunct professorships provide a better opportunity for getting a tenure-track job down the road than do non-teaching positions inside or outside of academia. Collectively these findings show that the academic life course is both complex and permeable.

\section{Introduction}

One of the most visible trends in higher education is the proliferation of temporary adjunct faculty. ${ }^{1}$ In 1975, instructors off the tenure track composed 43 percent of American faculty. By 2005, more than two-thirds were neither tenured nor tenure track (AAUP 2008). Furthermore, the majority of recent full-time academic hires have been off the tenure track (AAUP 2005). Adjunct positions have been assailed for their poor pay, low job security and lack of prestige compared to tenure-track appointments (Dubson 2001; Fountain 2005). They are the subject of numerous articles in the Chronicle of Higher Education. Academe and other industry

We thank Korey Capozza, Jerry Jacobs and Andrew Roth for helpful comments, Sonja Anderson and Alta Williams for research assistance, and the Alfred P. Sloan Foundation (2004-5-25 DLC) for its generous support of this project. The use of NSF data does not imply NSF endorsement of research methods or conclusions in this article. Previous versions of this paper were presented at the 2006 annual meeting of the American Sociological Association in Montreal, the 2006 Families and Work Conference at Brigham Young University and at the National Science Foundation in 2007. Direct correspondence to Nicholas H. Wolfinger, Department of Family and Consumer Studies, 225 South 1400 East, AEB 228, University of Utah, Salt Lake City, UT 84112-0080. E-mail: Nick.Wolfinger@fcs.utah.edu. 
publications. For many aspiring scholars, adjunct professorships are the academic graveyard, the place to go when all dreams of a tenure-track position have been extinguished.

This interpretation ignores an important role that may be served by employment off the tenure track: a springboard to a ladder-rank professorship down the road. Many Ph.D. recipients take adjunct teaching jobs. Do these positions hinder or facilitate movement to the tenure track? This research examines early career movement in and out of academia subsequent to Ph.D. receipt, with an emphasis on gender, family and adjunct positions. In particular, we seek to answer three questions: (1. Nationally representative data on 30,000 respondents from the 19811995 Surveys of Doctorate Recipients show that family formation, namely marriage and children, can account for the lower rate at which women become tenure-track professors (Mason, Goulden and Wolfinger 2006; Wolfinger, Mason and Goulden 2008). What kinds of positions do women hold instead? (2. Do marriage and children prevent women from obtaining tenure-track employment after pursuing other options out of graduate school? (3. What is the best job from which to obtain a tenure-track position after spending time off the tenure track?

On a theoretical level, we attempt to chart the normative professional life course for young scholars. The concept of the life course has been used to elucidate eclectic phenomena in the social sciences, including cohort effects (Elder 1999[1974]), becoming an adult (Hogan 1978, 1981). and the long-term consequences of early life conditions (Clausen 1991). A central tenet of these studies is the ordering of standard life events (George 1993; Elder and O'Rand 1995). Adverse consequences may result when these events do not occur in their customary sequence (Hogan 1978; Rindfuss, Swicegood and Rosenfeld 1987). We apply these notions to early academic careers to demonstrate the utility of the life course in understanding the intertwined processes of family formation and professional advancement in academia.

\section{Gender, Work-Family Conflict and the Tenure Track}

In the past 10 years two highly publicized events have highlighted the difficulties women face in the academy. The first, in 1999, was a comprehensive report on gender equity at MIT, which showed that female faculty systematically received inferior treatment (Massachusetts Institute of Technology 1999). The second took place six years later. In a published address former Harvard President Lawrence Summers (2005) suggested that biological differences might be a factor in accounting for the paucity of female faculty members at his institution. His remarks produced widespread backlash and media fanfare (New York Times 
2005). Both of these events focused renewed attention on the question of why there are so few female professors. Gender inequality has long been a pervasive feature of higher education (see Jacobs 1996 for a review), although recent years have seen noteworthy progress. From 1986 to 2004 the ratio of women to men in full-time faculty positions rose from less than .4 to more than .6 (on a scale where 1 indicates gender parity) (Academe 2005).

Traditional explanations for the gender gap in academia focus on discrimination (Carr et al. 2003; Valian 1998; West 1994). Proponents of this argument view the MIT report as confirmation of their suspicions, while Summers' remarks have been construed as evidence that some highly placed academics still harbor retrograde attitudes towards women (New York Times 2005). On the other hand, there are also many reasons to believe that discrimination within the professoriate is not pervasive; indeed, many academic departments and fields have apparently become more welcoming to women in recent years. Roos and Jones (1995). attempting to explain the poor representation of women in sociology, suggest that several factors should have led to more female sociologists than had been the case. First, the academic job market grew much weaker after 1970. Simultaneously, extramural funding from federal sources declined. These developments should have made academia less attractive to male job candidates, therefore increasing women's representation in the pool of aspiring professors. In addition, growing awareness about both affirmative action and gender inequities in the academic labor force, such as those depicted by the MIT report, has put increasing pressure on universities to hire women faculty.

Despite these developments, women's representation in academia has not increased apace with the dramatic growth in female Ph.D.s (cf. Sanderson and Dugoni 1999). There is ample evidence of discrimination, but there are also signs of various pressures that should have increased the number of women in tenure-track positions. For this reason it is useful to consider another explanation for the relative absence of women in academia: work-family conflict. This idea has received noteworthy attention recently. A 2004 issue of the Annals of the American Academy of Political and Social Science was devoted entirely to questions of how professional couples juggle work and family, with two articles focusing on academia (Jacobs and Winslow 2004a; Mason and Goulden 2004). Ample research now confirms that work-family conflict extends to academic households (Gatta and Roos 2002; O'Laughlin and Bischoff 2005), with female professors spending more time on domestic chores than their male counterparts (Mason and Goulden 2004; Suitor, Mecom and Feld 2001). It may interfere with a woman's ability to perform the research and teaching necessary for advancement in academia when her domestic 
responsibilities expand to include childrearing (Bassett 2005). Indeed, some female doctorate recipients avoid academic careers because of perceived barriers to parenthood (van Anders 2004).

Academic careers further conflict with family life by forcing new Ph.D.s to relocate in pursuit of tenure-track positions. Women with husbands and children often lack this flexibility, given that female faculty members are much more likely to have husbands with full-time jobs than vice versa. Fifty-six percent of male faculty members have spouses that are employed fulltime, compared to 89 percent of female faculty members (Jacobs 2004). Female academics are also more likely to be married to male academics than vice versa (Astin and Milem 1997; Jacobs 2004), so women may forsake their own academic careers in order to facilitate those of their husbands. Female academics are more likely than their male counterparts to reside in large cities and other areas with multiple colleges and universities (Kulis and Sicotte 2002), suggesting that dual career constraints limit women's ability to assume and retain professorships (Wolf-Wendel, Twombly and Rice 2003).

Finally, it should be acknowledged that family formation may give rise to discrimination directed solely against married women and women with children. Correll, Bernard and Paik (2007) recently showed that employers discriminate against mothers in numerous ways. It is hard to know whether this finding extends to academia, traditionally heralded as more progressive and open-minded than society at large. Furthermore, discrimination is notoriously difficult to prove. Nevertheless, we should keep in mind the possibility that perceived work-family conflict in academia actually represents discrimination against mothers and motherhood.

\section{Adjunct Professorships: The "Mommy Track"?}

Besides gender equity, few issues are more frequently debated in the academy than the proliferation of adjunct professorships. These discussions should not be conducted separately. Instructors, lecturers and other unranked faculty compose 22 percent of all female full-time faculty, but only 11 percent of male faculty (Curtis 2004; see also Perna 2001). Moreover, the proportion of adjunct faculty increased over the same years as did the proportion of women in academia (cf. Academe 2005; Curtis 2005). Although an increasing number of women now hold tenure-track professorships (Academe 2005), they remain overrepresented among adjunct faculty.

There is a class of adjuncts with good outside jobs, who teach only one or two courses at a time (Academe 2005). For these individuals, teaching provides intellectual stimulation and extra income. However, they represent a minority. For most adjuncts, teaching is a full-time profession and their 
primary source of income (AAUP 2005); about half work more than 50 hours a week (Jacobs 2004). ${ }^{2}$ Their marginal status within academia is well established; one need only invoke the title of Wendell Fountain's (2005) book, Academic Sharecroppers, to make this point. Adjunct faculty are paid 26 percent less than comparable tenure-track assistant professors (Monks 2004). They are less likely to get the offices, computers and other resources that ladder-rank faculty routinely receive. They are unlikely to advise students. Finally, the proliferation of adjunct professorships compromises the basic mission of American higher education. Because adjunct faculty are not subject to the same scrutiny as tenure-track professors, student learning may suffer (AAUP 2005; Benjamin 2002). Many adjuncts are excellent teachers, but there are rarely mechanisms in place to prevent inferior instructors from joining their ranks. The other component of higher education to suffer is academic freedom: lacking both the security of tenure and a greater stake in the academic system, adjunct instructors have less protection and less incentive to defend the intellectual and moral prerogatives of the professoriate (AAUP 2005).

Adjunct faculty, in short, are second class citizens in almost every respect. They represent an academic analog of the "feminization of poverty," given that adjuncts are disproportionately likely to be women. Because we now know that family formation accounts for the lower rate of women in tenuretrack professorships (Mason, Goulden and Wolfinger 2006; Wolfinger, Mason and Goulden 2008), it is logical to determine whether it can also explain why they are more likely to become adjuncts. We speculate that non-ladder rank positions may offer various benefits to female Ph.D. holders that are unavailable in tenure-track jobs. First, they provide the option of part-time employment, something very rarely found in a tenuretrack position. This may be attractive to women with children. Besides the possibility of lighter teaching loads, these positions do not offer tenure and therefore do not require burdensome work hours for an extended probationary period. Second, adjunct professorships are readily available and therefore may be sought out by married women, whose geographic mobility is frequently constrained by their husbands' careers. Relying on their husbands' incomes, married Ph.D.s may be able to make do with the lower salary of an adjunct position. For these reasons we anticipate that married women and women with young children will be especially likely to be employed in adjunct professorships rather than tenure-track jobs.

Our next question concerns how academics go about reentering the tenure track after they leave it. ${ }^{3}$ In particular, are adjuncts doomed to remain in their second-tier jobs until they leave academia? For people who are not employed in tenure-track professorships straight out of graduate school, what is the best job for those who ultimately want such a position? Perhaps adjunct employment is desirable as the career choice 
physically and intellectually closest to tenure-track employment: "staying in the game" might make it easier to secure a tenure-track position down the road. Alternately, the stigma of failing to get a job straight out of graduate school - perhaps often presumed to be the impetus for adjunct employment - may make it difficult to get a permanent academic job later on. Other types of work, in government or the private sector, may not bear the same stigma. Our analysis will determine the best careers for doctorate recipients who ultimately aspire to ladder-rank positions.

Our final question concerns the kinds of people most likely to get tenuretrack positions after spending time in adjunct professorships, other jobs or out of the paid labor force. Since family formation explains the lower rate at which women get tenure-track jobs out of graduate school, can it also predict which women eventually return to the tenure track? There are at least three possibilities here. First, women who are not employed in ladder-rank jobs right out of graduate school may be permanently moving towards a less demanding career course, one that does not require the long hours and rigid probationary period of a tenure-stream academic appointment. It is also possible that not having tenure-track employment right after graduate school forecloses the opportunity down the road. Ph.D.s get "stale." Scholars do not stay current in their fields and do not publish. Alternately, women may work in adjunct professorships temporarily, perhaps to raise children until they reach school age. At this point, mothers attempt to secure tenure-track jobs.

Little research has considered the effects of time out of the labor force. Only one study has examined academic time-outs: Analyzing a sample of 250 faculty members in the social sciences, McElrath (1992) found that women who take time off are less likely to be promoted. Her respondents were already ladder-rank faculty, so her findings do not shed light on academicians who have stepped off the tenure track. Noonan and Corcoran (2004) show that female lawyers who take breaks earn less and are less likely to make partner. In later work, Noonan (2005) finds that time out reduces salaries for all women (see also Hewlett and Luce 2005).

The unique career structure of academia offers women no good opportunity to take time out for children. After four to eight years in graduate school, assistant professors have about six years to publish or perish. Only after tenure and promotion from assistant to associate professor are faculty assured of job security. The median doctorate recipient is already 33 or 34 years old (Jacobs and Winslow 2004b; Hoffer et al. 2001); after a probationary assistant professorship, close to 40 . In terms of career development this would be an ideal time for female professors to start their families, but biologically they are already past prime childbearing age. Women ages 35-39 and older have almost quadruple the likelihood of having babies with Down's Syndrome compared to women in their 
20s (California Birth Defects Monitoring Program 2005). Graduate school may not be an optimal time to have children, both because of the work load and the probable lack of a steady income. The solution for aspiring academics may be an adjunct professorship for a few years, until children are school age. Our analysis will determine whether this is a viable route to a tenure-track job.

\section{Pipeline vs. Life Course}

To the best of our knowledge previous studies have not discussed academic careers in terms of the life course. Instead, a common theoretical framework has been the pipeline (e.g., Kulis, Sicotte, and Collins 2002; Long 2001; van Anders 2004). The pipeline, applied especially frequently to the careers of bench (or "hard") scientists but also to academia in general, implies a lock-step sequence of events that can begin as early as high school (cf. Widnall 1988). At this stage, women may be underrepresented in the courses that might ultimately prepare them for scientific careers. More often, the pipeline to academic success is said to begin in graduate school. An academic job requires a doctorate; scholars cannot normally become full professors without first serving as assistants and then associates. Each of these positions represents a stage in the pipeline that academics must pass through in order to rise to the top of the profession, commonly defined as a tenured full professorship.

Many scholars have been critical of the pipeline model. Writing about sex segregation in the workforce, Jacobs (1989) rejected the pipeline for a "revolving door" model of women's entrance into male-dominated professions. More recently, Moen (2003) suggested that the linear, lockstep career path was an outdated notion. Hewlett and Luce (2005) echoed this contention by calling for more "on-ramps," means by which women could return to the workplace after the "off-ramps" of pregnancy and childrearing. Xie and Shauman (2003), writing explicitly about scientists' careers, assailed the pipeline model on several counts. Two of their criticisms are particularly relevant for our research. The first is the failure of the pipeline model to provide any mechanism for reentry after "leaking" out:

"...the pipeline model is a developmental framework in which the successful completion of all stages within an ideal time schedule means a positive outcome. Nonparticipation at any stage is equated with dropping out of the pipeline, and movement back into the pipeline after dropout is assumed to be structurally improbable or impossible. Thus, the narrowness of this model has precluded the consideration of alternative 
educational and career trajectories..."

(Xie and Shauman 2003:8-9)

A key objective of our research is to evaluate reentering the faculty pipeline as a feature of alternative professional trajectories. Xie and Shauman's (2003) second point concerns the failure of the pipeline model to incorporate the effects of life course events other than schooling and jobs. As we have suggested, family formation has profound effects on women's academic careers.

With a focus on the normative order of life events (Elder 1994, 2002; Elder and O'Rand 1995; George 1993), the life course is a natural alternative to the pipeline:

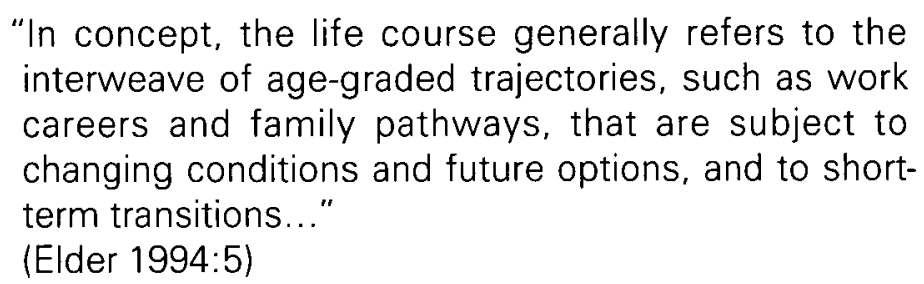

Thus the life course provides a theoretical framework for exploring the connection between work and family in academia, a set of potential relationships seemingly precluded by the pipeline model (Xie and Shauman 2003). The life course emphasis on normative order provides a warrant for exploring deviations from the normative: how moving out of the tenure stream, by taking an adjunct professorship or any other means, ultimately affects the likelihood of returning to the tenure-track. This will facilitate our understanding of how young doctorate recipients go about achieving tenure-track academic careers. We also hope to contribute new insight about the sequencing of work and fertility in the life course (cf. Budig 2003).

\section{Methods}

\section{Data}

For more than 40 years all new Ph.D. recipients in the United States have been administered questionnaires, comprising the Survey of Earned Doctorates. Since 1973, approximately 10 percent of Survey of Earned Doctorates respondents have been selected for ongoing biennial interviews that continue until age 76 or relocation outside of the United States. Together the repeated interviews of new and former Ph.D. recipients compose the Survey of Doctorate Recipients (National Science Foundation 2003). The result is a large and continually replenished set of 
panel data on academic careers. We analyze data for respondents queried from 1983 through 1995, inclusive; questions about family formation were not asked in earlier years, and later years omit humanities Ph.D.s. due to budgetary constraints. Our primary sample sizes are 16,049 for analysis of first post-Ph.D. job and 6,501 for analysis of returns to the tenure track. Overall response rates are good: 87 percent of respondents completed the survey in 1991 (National Science Foundation 1995).

Multivariate analyses employ survey weights that adjust for attrition bias in order to make the data representative. To avoid artificially inflated t-ratios in our significance tests we compute Huber-White standard errors (Winship and Radbill 1994). Missing data are deleted listwise, except when they may represent substantively meaningful differences between respondents. For these items, including race, time to complete Ph.D. and quality of degreegranting institution, we code additional dummy variables for missing data. More sophisticated means of handling missing data, such as multiple imputation, do not perform appreciably better (Paul et al. 2008).

\section{Variables}

We analyze two dependent variables. The first is the initial type of employment (or non-employment) reported by respondents subsequent to Ph.D. receipt. Generally this is measured two years after leaving graduate school, although certain conditions may delay assessment. This is a nominal variable with five categories: tenure-track employment (the reference category), adjunct teaching appointment, non-teaching employment within a college or university (including administrative and research positions), employment outside higher education and being out of the paid labor force. Tenure-track employment is the reference category because it is a normative stage in the traditional academic career and therefore a focus of this study. Since the first interview takes place two years after respondents get their degrees, year-long stints as adjuncts or research associates, common means of subsistence while scholars are on the academic job market, are not captured by our dependent variable. For the 11 percent of respondents in post-docs at their first SDR interviews we analyze their first non-postdoctoral employment. Summary statistics for all variables appear in Appendix A.

The second dependent variable is time to reentry: getting a tenure-track job after spending time in one of the four non-tenure-track states. This is coded as a set of event histories.

Our primary independent variables are respondent sex, fertility and marital status. Marital status is measured with a single dummy ascertaining whether a respondent is currently in a heterosexual marriage (the data predate same-sex marriage in California, Connecticut and Massachusetts): 
unfortunately it is not possible to know whether unmarried respondents have live-in partners. In addition, the SDR does not indicate whether respondent spouses are employed as faculty. Fertility is measured with a pair of dummy variables, assessing the presence of children under 6 and children 6-18. Children under 6 pose a greater barrier to professional advancement than do school-age offspring (Wolfinger, Mason and Goulden 2008). In preliminary analyses we experimented with variables measuring numbers of children, but these did not produce substantially different results. Both marital status and children are time-varying covariates in analyses of time to reentry. These analyses include an additional timevarying independent variable, a set of dummies measuring whether respondents are currently: in adjunct professorships, working at a college or university in a non-teaching capacity, or employed outside higher education; out of the labor force is the omitted category.

Control variables fall into two categories, academic and demographic characteristics. Any of these may be correlated with both respondent family formation behaviors and the outcomes we consider. Academic controls include the National Research Council ranking of respondents Ph.D. programs (cf. Allison and Long 1987), time to doctoral degree, doctoral field, time since completion of graduate school, calendar year of Ph.D. receipt, and whether a respondent held a post-doctoral fellowship prior to his or her first post-Ph.D. employment (or departure from the labor force). The first two are coded as sets of dummy variables, representing quartiles of the observed continuous variables; field of employment is a trichotomous variable measuring whether respondents received their degrees in the humanities, social sciences or bench sciences (including the biological and physical sciences, engineering, and mathematics). Year of $\mathrm{Ph}$.D. receipt, measured with a continuous variable, is intended to account for cohort effects in our data. Time since Ph.D. receipt, also continuous and used only in the models predicting initial employment status, accounts for delays produced by post-docs, Fulbrights and other temporary assignations following the completion of graduate school. This variable is omitted from analysis of reentry because of its correlation with time-to-event.

A dummy variable measures whether respondents held one or more post-doctoral fellowships prior to becoming an adjunct or tenure-track faculty member, becoming otherwise employed inside or outside higher education, or exiting the paid labor force. We view postdoctoral fellowships as the last stage of respondents' education, not the first stage of their careers (see Cobb and Krosnick 2007). A post-doc is by definition temporary. Unlike with adjunct teaching positions, scholars are unlikely to string them together perpetually to provide permanent employment lat least in the social sciences and humanities). Therefore they do not belong with the five employment states listed above; indeed, a post-doc may be a 
precursor to any of them. In preliminary analysis we explored interactions between respondent sex and having held a post-doc, but they were nonsignificant and omitted from the results presented here.

Demographic controls include race and age. Race is dummy-coded with variables measuring whether a respondent is black, white, Latino, Asian or other; age is continuous and time-varying in the analysis of returns to the tenure track. In the analysis of first job type, it is measured at the same time as employment status.

\section{Analyses}

First employment is a five-category nominal variable analyzed using multinomial logistic regression. The independence of irrelevant alternatives assumption was verified by both Hausman and Small-Hsiao tests (Powers and Xie 2000). Next, we examine the likelihood of reentry-getting a ladderrank job after initial employment off the tenure track - using discrete timeevent history models estimated via complementary log-log regression. The complementary log-log is a better estimator than logit or probit when discrete data approximate a continuous time process (Allison 1995). Since time-to-event is measured in years, continuous time models would be difficult to estimate.

Data from each wave of the SDR 1983-1995, inclusive, are used to construct event histories of time to tenure-track employment. For each year in any non-tenure-track employment status following Ph.D. receipt, an additional record is created. Failure occurs when respondents obtain tenure-track jobs. The hazard function is captured by a dummy variable for each year prior to a tenure-track job. Based on preliminary analyses we top-code the duration dependence dummies at six. Few respondents obtained tenure-track jobs after six years, so models lacking the top-code could not be estimated.

We estimate a single model for reentry from the four non-tenuretrack states (adjunct teaching appointments, non-teaching university employment, employment outside higher education, and not in the labor force): heterogeneity between the four states is captured with the aforementioned set of dummy variables. Sample size limitations preclude separate event history models for each state (or separate models for different academic fields).

Two models are estimated for each of our two dependent variables. The first model in each pair contains measures of sex, family formation, demographic and academic characteristics. Next we interact respondent sex with the family formation variables (and, for the reentry models, current employment status) in order to show how marriage and children differentially affect men's and women's academic careers. We observed 
no statistically significant three-way interactions between sex, marital status and the presence of children, as well as no interactions involving marriage for the analysis of reentry.

\section{Results}

\section{Leaving the Tenure Track}

Ph.D. recipients experience five different career outcomes: (1. tenuretrack employment; (2. adjunct professorships; (3. non-teaching jobs at institutions of higher learning; (4. non-academic employment; and (5. exiting the labor force. Table 1 shows how respondent sex, presence of children, marital status and other characteristics affect the relative likelihood of these outcomes. "Tenure-track employment" is the omitted category on our dependent variable, so we report coefficients that represent the probability of each outcome relative to the chances of getting a tenure-track job. Model 1 shows results that are both logical and unanticipated. Women are 43 percent more likely than men to have adjunct jobs and not tenure-track positions $(\exp [.36]=1.43)$. On the other hand, respondents with young children are 20 percent $(1-\exp [-.22]=$ .80) less likely to become adjuncts. In most other respects the results are predictable. Respondents who attend middling graduate programs are more likely to become contingent faculty, as are people who took longer to get their Ph.D.s. Blacks are less likely to become adjuncts compared to members of other population groups. Having a post-doc is correlated both with becoming an adjunct faculty member and leaving the labor force.

Aside from adjunct professorships, certain other career destinations are common among women who are not employed in tenure-track positions right out of graduate school. According to Model 1, female doctorate recipients are 25 percent $(\exp [.22])=1.25)$ more likely to be employed in non-teaching university positions than they are tenure-track jobs. Compared to men, women are 9 percent less likely to work outside academia entirely $(1-\exp [-.09]=.91)$, although the relationship is only marginally significant $(p=.058)$. Furthermore, female Ph.D.s are 156 percent $(\exp [.94]=2.56)$ more likely to be out of the labor force than they are to have tenure-track jobs.

It has long been known that women are far less likely than men to get tenure-track academic appointments (National Center for Education Statistics 2001). Our results shed light on their other career paths. Compared to men, women who do not secure ladder-rank appointments are more likely to stay in academia, either as adjuncts or in non-teaching positions, and less likely to be working in non-academic jobs. Also, they are more likely to be out of the labor force. Married respondents and those 


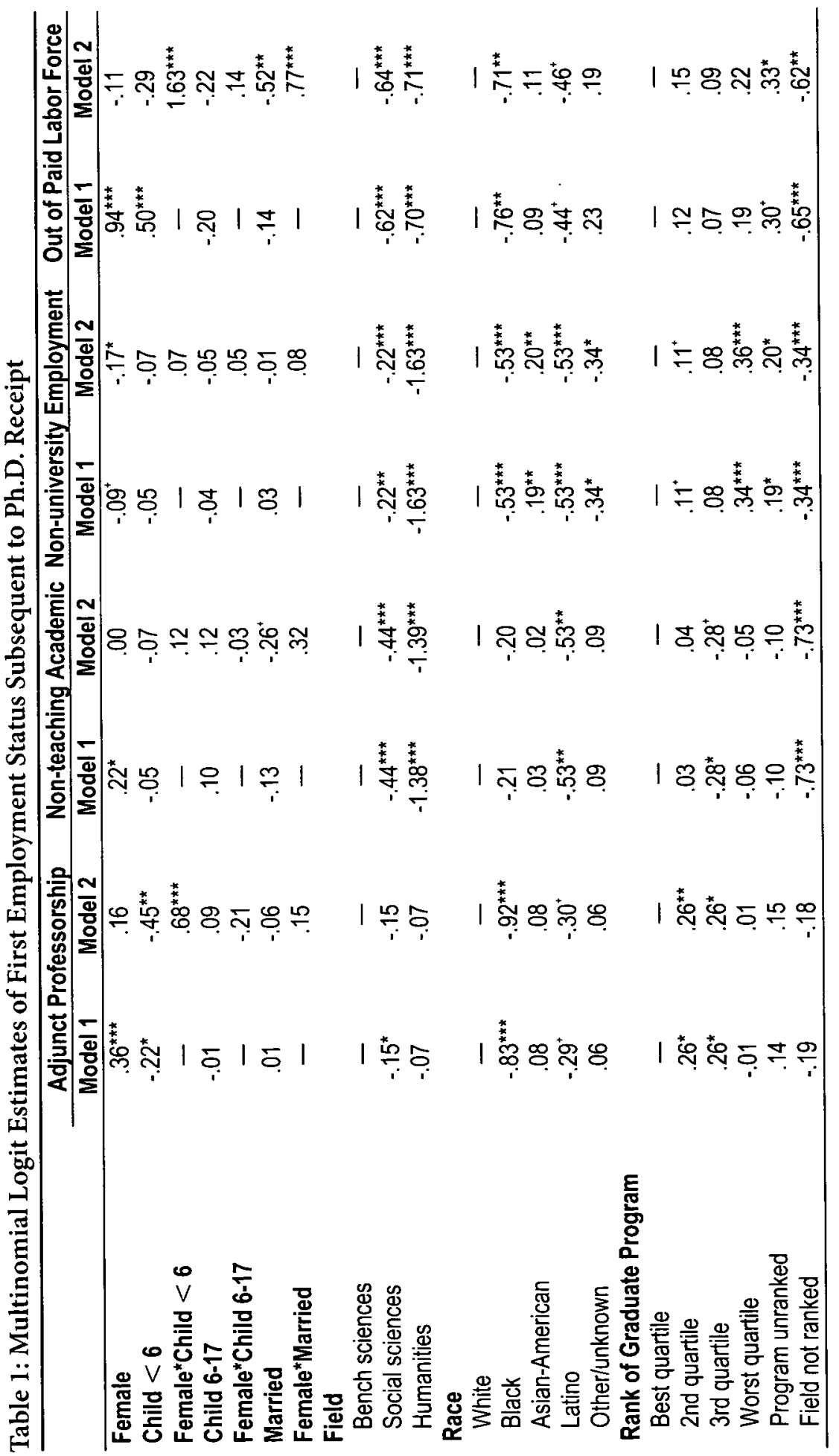


1604 - Social Forces 87(3)

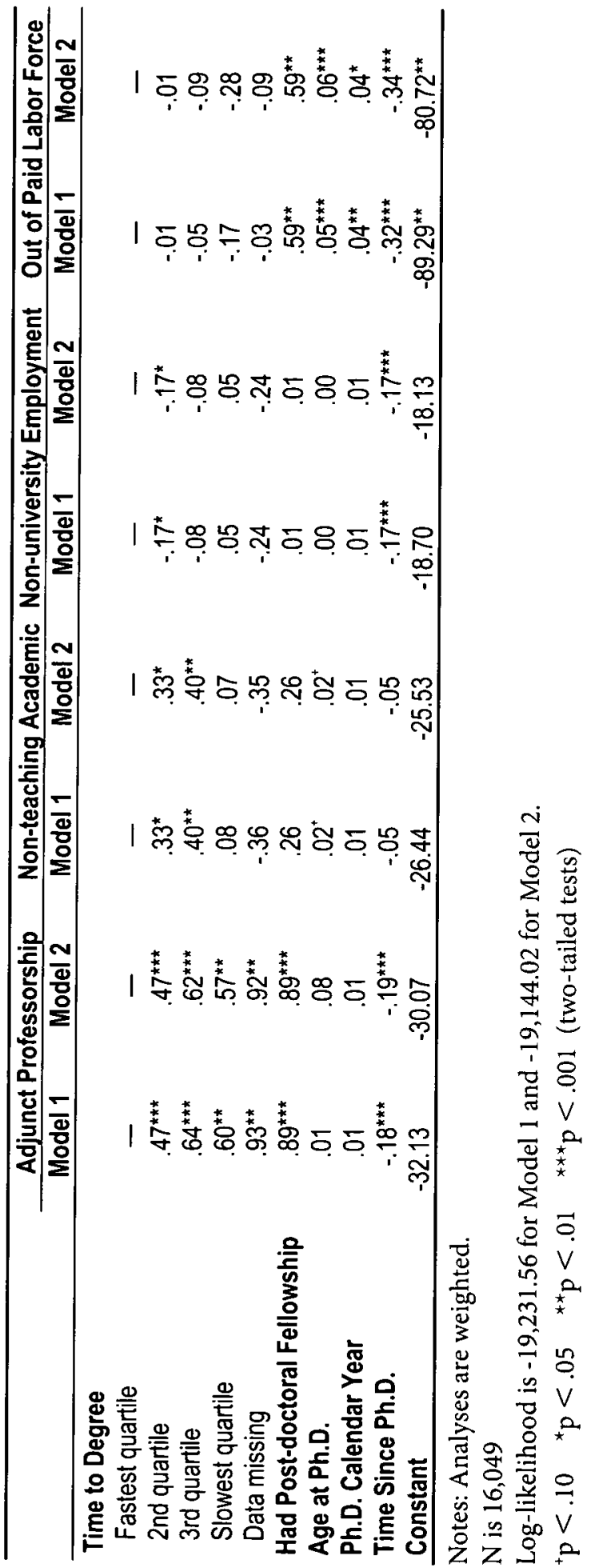


Figure 1. The Relative Odds of Having an Adjunct Position Rather Than a Tenure-Track Job, Relative to the Odds for a Single Childless Man

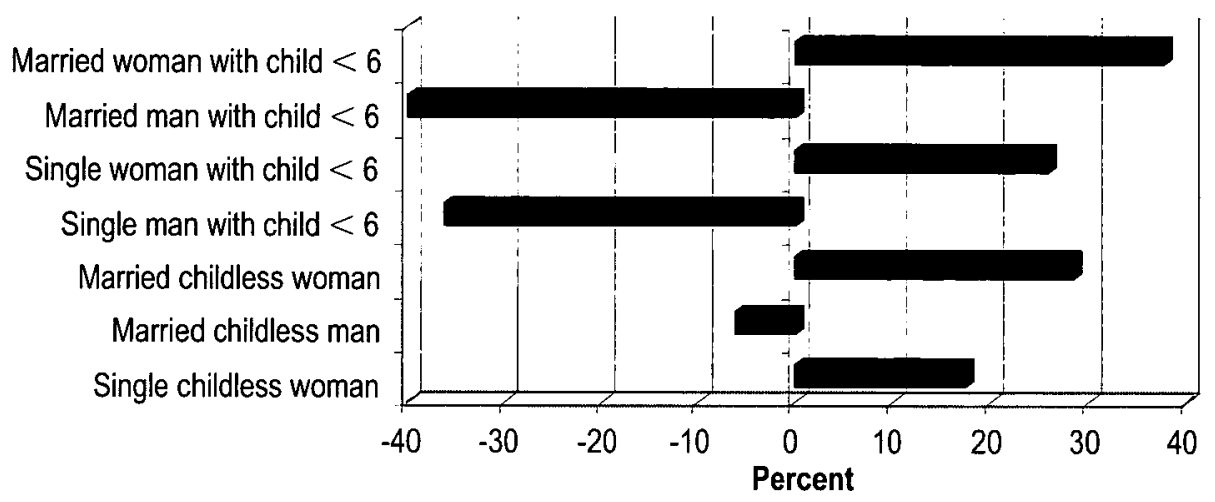

Note: Results for marriage not statistically significant.

with children, young or older, are no more or less likely to be working in non-teaching academic jobs or employed outside academia. Predictably, recent Ph.D.s with young children are 65 percent more likely than their counterparts without preschool-age children to be out of the paid labor force rather than in tenure-track positions (exp[.50] $=1.65$ ).

Many of these results vary substantially by respondent sex. Model 2 adds interactions between sex and measures of family formation, marriage and the presence of children; the effects of these interactions on adjunct employment are summarized in Figure 1. Two employment patterns are especially common among women with families. Women with children under age 6 are disproportionately likely to be employed in adjunct professorships, based on the large and statistically significant interaction term between sex and the presence of a young child. A woman with a child under 6 is 26 percent more likely to be employed in an adjunct professorship rather than a tenure-track position in comparison to her childless counterpart (exp[.68 -.45$]=1.26)$. Compared to a man with a young child, she is 132 percent more likely to be working in an adjunct position $(\exp [.68+.16]=2.32)$. Conversely, a male Ph.D. with a young child is 36 percent less likely to become an adjunct instead of a tenure-track professor $(1-\exp [-.45]=.64)$. Children apparently have different effects on the career paths of male and female parents subsequent to graduate school. For men, young children push them to obtain more lucrative and potentially secure employment, either via tenure-track positions or outside academia altogether. In contrast, young children lead female doctorate recipients to work in less demanding, more flexible, but lower-status adjunct professorships. 
Predictably, the other common career path for female Ph.D.s with young children is to leave the paid labor force. Women with children under 6 are almost four times as likely to leave the labor force in lieu of a ladder-rank professorship in comparison to women without young children $(\exp [1.63-.29]=3.82)$. Male parents with young children do not exit the paid labor force in such numbers. Marriage also leads women to leave the labor force, as demonstrated by the statistically significant interaction between gender and marriage. Compared to an unwed women, her married counterpart is 28 percent more likely to not work $(\exp [.77-.52]=1.28)$. Neither marriage nor the presence of young children has any such effect for men; indeed, both increase the likelihood of taking a tenure-track job over departing the labor force.

Together, marriage and childbirth largely account for why female doctorate recipients exit the labor force rather than obtain ladder-rank positions. A single woman without children under six is only 10 percent less likely to be unemployed right out of graduate school than she is apt to have a tenure-stream job. The same holds true for the likelihood that she gets an adjunct rather than tenure-track position. Recall that women in general are 45 percent more likely to be in adjunct positions. However, a single woman without young children is only 17 percent more likely to have a second-tier job $\exp [.16]=1.17)$. It had already been established that family formation can account for the lower rate at which women become tenure-track faculty members (Mason, Goulden and Wolfinger 2006; Wolfinger, Mason and Goulden 2008). We now know where they go instead: adjunct professorships and out of the labor force.

\section{Returning to the Tenure Track}

Figure 2 plots smoothed life table failure rates for returns to the tenuretrack within the first 10 years of leaving (in other words, the cumulative likelihood of getting a tenure-track job for Ph.D.s whose first postdoctoral positions were off the tenure-track). Sample size considerations prevent us from considering later reentry; in any event, almost all returns occur within a decade. Overall, only one out of four people who get off the tenure track ever return (By way of contrast, 35 percent of recent doctorates obtain tenure-track jobs as their first non-post-doc employment subsequent to graduate school.) But this figure conceals considerable variation by type of postdoctoral employment. More than half of all Ph.D.s employed as adjuncts right after graduate school manage to get tenure-track jobs within 10 years. Reentry rates are also relatively high for people employed at colleges and universities in jobs that do not involve teaching. In contrast, unemployed Ph.D.s return to the tenure-track at lower rates; the lowest, at about 10 percent, are reserved for people employed outside academia. 
Figure 2. Reentry Rates for Ladder-Rank Employment after Time off the Tenure Track

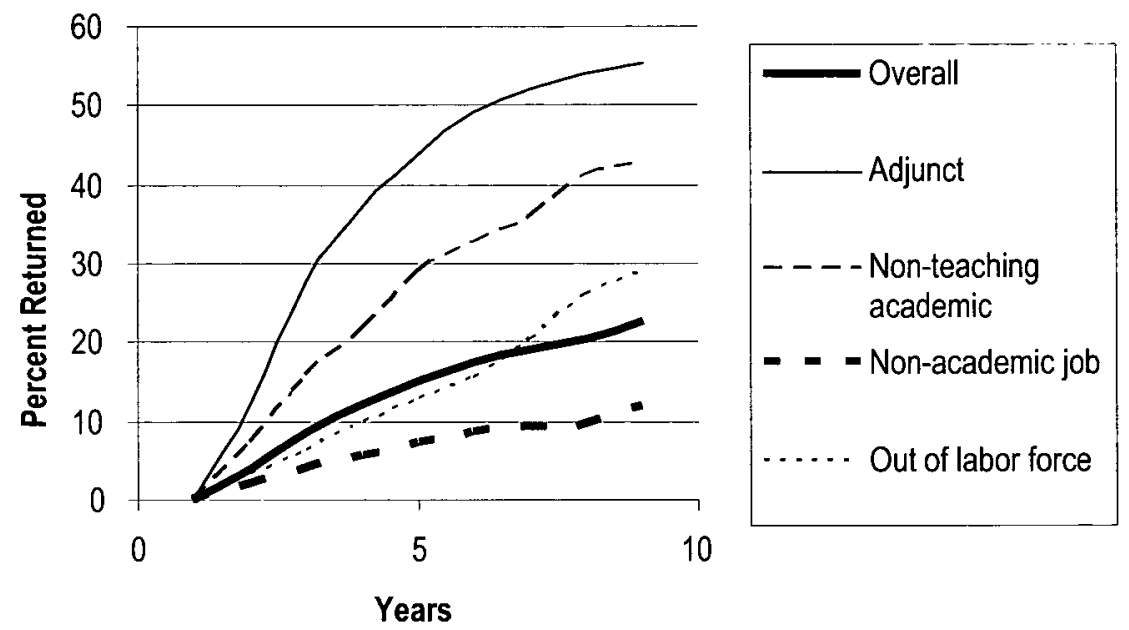

The implication of these results is straightforward: the rigid pipeline model no longer fits academia. Many people who exit the academic pipeline will subsequently reenter it. In particular, people remaining involved with higher education are much more likely to get tenure-track jobs down the road. Taking an adjunct teaching position after graduate school does not ruin one's prospects for an academic career.

Most people who return to the tenure track do so within a few years of leaving. Figure 3 shows hazard rates (that is, duration-specific likelihoods) for getting a tenure-track job for Ph.D.s whose first post-doctoral position was off the tenure track. Overall, the likelihood of a tenure-track job is greatest between two and four years after Ph.D. receipt. Thereafter the probability of reentry steadily declines. This pattern is most pronounced for people in adjunct professorships, for whom the likelihood of a tenuretrack position plummets after three years. In contrast, rates of reentry are consistently low for people with jobs outside academia. The only respondents whose prospects appear to rise over time are those who leave the labor force subsequent to Ph.D. receipt. As the results presented below suggest, these may be parents raising young children.

What kinds of Ph.D. recipients return to the tenure-track? Table 2 shows the results of the event history analyses predicting the likelihood of getting a ladder-rank academic position for respondents whose initial postdoctoral employment was off the tenure track. Looking first at Model 1 , we observe that neither of the characteristics motivating this study gender and family formation - predict reentry. The coefficients for women, children and marriage are all small and statistically insignificant. On the other hand, various other respondent attributes affect the likelihood of 
Figure 3. Hazard Rates for Ladder-Rank Employment after Time off the Tenure Track

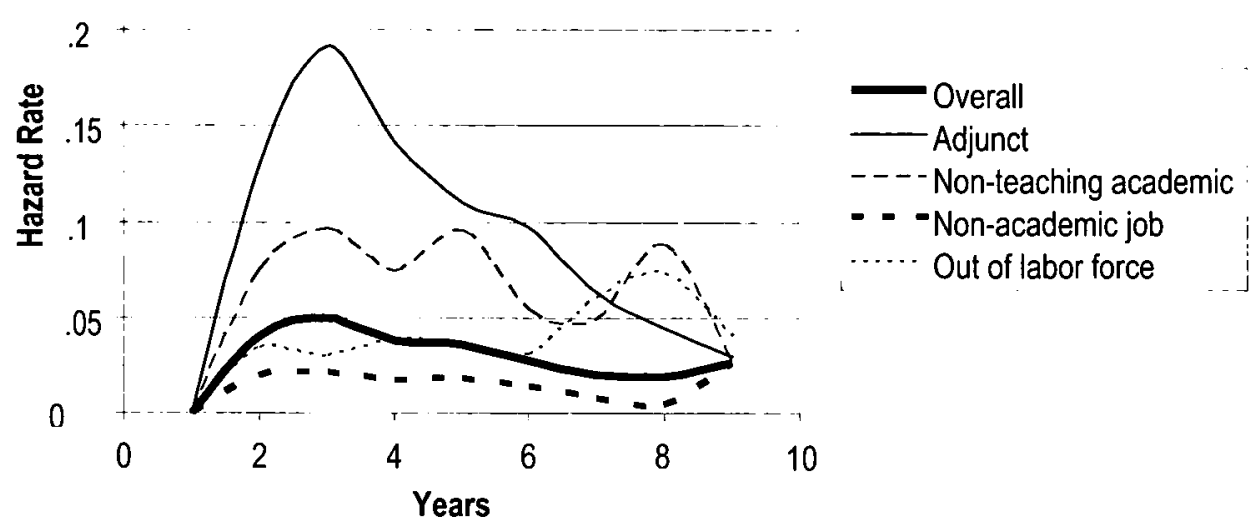

moving into a tenure-track job. Respondents with Ph.D.s in the humanities, lacking the career options of people in the social and bench sciences, are especially likely to land tenure-track positions. The odds of returning are greater for people receiving their doctorates in recent years. Older respondents are less likely to return. In accordance with Figure 3, the chances of getting back on the tenure-track are highest within five years of leaving it; thereafter, the odds drop 33 percent $(1-\exp [-.40]=.67)$.

Of greater interest are the results measuring previous employment status. The estimated coefficients contrast the likelihood of securing a tenure-track (or, very rarely, tenured) position in comparison to doctorate holders who have left the labor force. Of these respondents, adjunct faculty members have by far the highest rate of reentry: they are four times as likely to move into ladder-rank positions as are unemployed Ph.D. recipients $(\exp [1.41]=4.10)$. People working in non-teaching academic positions also get tenure-track jobs at a high rate, with a hazard ratio of 164 percent $(\exp [.97]=2.64)$. On the other hand, people employed outside academia are 47 percent less likely to return than are unemployed Ph.D.s (1 - exp[-.63] $=.53$ ). Between adjuncts and non-teaching academic employees, adjuncts are more likely to have ladder-rank positions: we repeated our analysis with "non-teaching academic" as the reference category and found that adjuncts are 62 percent more likely to land tenure-track jobs $(p<.01) .^{5}$

These results make sense. People who stay at colleges and universities, via adjunct professorships or other forms of academic employment, are the most likely to move into tenure-track positions. There is no way to determine causality: we cannot know whether Ph.D.s who want ladder-rank 
Table 2: Discrete-time Event History Estimates for Tenure-Track Job Receipt Subsequent to Leaving the Tenure Track

\begin{tabular}{|c|c|c|}
\hline & Model 1 & Model 2 \\
\hline Female & -.10 & $-.64^{+}$ \\
\hline Child $<6$ & .03 & .17 \\
\hline Female ${ }^{*}$ Child $<6$ & - & $-.44^{*}$ \\
\hline Child 6-17 & -.02 & $-.31^{+}$ \\
\hline Female ${ }^{\star}$ Child 6-17 & - & $.81^{\star \star}$ \\
\hline Married & .03 & .04 \\
\hline \multicolumn{3}{|l|}{ Employment Status } \\
\hline Adjunct professorship & $1.41^{\star \star \star \star}$ & $1.16^{\star \star *}$ \\
\hline Non-teaching academic & $.97^{\star \star \star}$ & $.89^{* \star}$ \\
\hline Non-university employment & $-.63^{\star \star}$ & $-1.00^{\star \star}$ \\
\hline Not in paid labor force & - & - \\
\hline Female ${ }^{\star}$ Adjunct Professorship & - & .53 \\
\hline Female*Non-teaching Academic & - & .05 \\
\hline Female*Non-university Employment & - & $.90^{*}$ \\
\hline \multicolumn{3}{|l|}{ Field } \\
\hline Bench sciences & - & - \\
\hline Social sciences & $.31^{*}$ & $.31^{*}$ \\
\hline Humanities & $.51^{* \star *}$ & $.52^{* * *}$ \\
\hline \multicolumn{3}{|l|}{ Race } \\
\hline White & - & - \\
\hline Black & $.54^{+}$ & $.54^{\circ}$ \\
\hline Asian-American & -.24 & -.24 \\
\hline Latino & .22 & 19 \\
\hline Other/unknown & -.40 & -.42 \\
\hline \multicolumn{3}{|l|}{ Rank of Graduate Program } \\
\hline Best quartile & - & - \\
\hline 2nd quartile & -.06 & -.07 \\
\hline 3rd quartile & .07 & .05 \\
\hline Worst quartile & -.26 & -.27 \\
\hline Program unranked & -.33 & $-.35^{+}$ \\
\hline Field not ranked & $.35^{\circ}$ & $.30^{+}$ \\
\hline \multicolumn{3}{|l|}{ Time to Degree } \\
\hline Fastest quartile & - & - \\
\hline 2nd quartile & .07 & .08 \\
\hline 3rd quartile & .03 & .01 \\
\hline Slowest quartile & -.23 & -.21 \\
\hline Data missing & -.40 & -.45 \\
\hline Had Post-doctoral Fellowship & $.88^{\star \star \star}$ & $.57^{\star \star \star}$ \\
\hline Age at Ph.D. & $-.03^{\star *}$ & $-.04^{\star \star}$ \\
\hline Ph.D. Calendar Year & $.07^{\star \star}$ & $.07^{\star \star}$ \\
\hline
\end{tabular}


Table 2 continued

\begin{tabular}{lcc}
\hline & Model 1 & Model 2 \\
\hline Duration Dependence & & \\
Year 1 & - & - \\
Year 2 & $.23^{+}$ & $.23^{+}$ \\
Year 3 & .12 & .13 \\
Year 4 & .09 & .12 \\
Year 5 & -.08 & -.15 \\
Year 6+ & $-.40^{+}$ & $-.43^{+}$ \\
Constant & $-140.87^{\star \star}$ & $-143.81^{\star \star}$ \\
Log-likelihood & -35319.40 & -35083.82 \\
\hline
\end{tabular}

Notes: Analyses are weighted. $\mathrm{N}$ is 6,$501 ; 21,435$ person years.

${ }^{+} \mathrm{p}<.10{ }^{*} \mathrm{p}<.05 \quad{ }^{* *} \mathrm{p}<.01 \quad{ }^{\star *} \mathrm{p}<.001$ (2-tailed tests)

positions intentionally "stay in the game" by taking untenured university employment, or if proximity produces contacts, research opportunities and other sorts of professional capital that can ultimately lead to tenure-stream job offers. Conversely, people leaving academia for outside employment may have little incentive to return, or may never have intended to remain in academia in the first place.

Model 2 adds interactions between respondent sex and various independent variables to the analysis. Collectively these interactions offer two contributions to our understanding of the academic life course. First, they reveal noteworthy gender differences in the kinds of post-Ph.D. employment likely to lead to a tenure-track position down the road. Recall that people employed outside academia had the lowest rate of reentry, lower even than the rate for unemployed Ph.D.s (Model 1). The statistically significant sex interaction in Model 2 shows that this is true only for men; women employed outside academia have reentry rates only 10 percent lower than do unemployed female doctorate recipients ( 1 - exp[.90-1.00) $=.90$ ). Some women working in jobs outside academia may be doing so only provisionally, until their children reach school age. In contrast, men who leave academia tend to stay out. More likely to be their family's primary wage earners, these men may hesitate to forsake stable careers outside academia for the vicissitudes of a tenure-track professorship. Alternately they may have anticipated nonacademic careers all along.

What family formation variables affect women's returns to academia? This is the second question addressed by Model 2. In particular, there are statistically significant interactions between respondent sex and the presence of both young and old children. Women with children under six are 24 percent less likely to move into ladder-rank jobs compared to 
women without young children $(1-\exp [.17-.44]=.76)$. Furthermore, mothers of young children are 66 percent less likely to enter the tenuretrack than are comparable fathers $(1-\exp [-.64-.44]=.34)$. These results show that the presence of preschool-age children is an important reason why women who leave the tenure track stay off it. In addition, the results presented in Table 2 and Figure 2 show that the longer people stay off the tenure track, the harder it is to return. Both chronological age and time elapsed since leaving graduate school decrease the likelihood of getting a ladder-rank academic position. School-age children have the opposite effect. Women with children 6 and older have substantially higher rates of reentry, being 65 percent more likely to move into tenure-track jobs than are childless women $(\exp [.81-.31]=1.65)$.

These results offer insight into how men and women who leave the tenure track go about returning. Women do not start ladder-rank positions when they have young children (and, perhaps, when children are incipient). They stay off the tenure track until their kids reach school age, at which point their rates of reentry increase. Returning is always harder than moving straight through the pipeline to ladder-rank employment after graduate school (or after post-doctoral fellowships, depending on the field). These patterns are reversed for men: they are more likely to have tenure-track positions when they have young children. Presumably their wives or partners will provide childcare. Fathers may also object less to geographical relocation when their children are young and less likely to have their school and social lives disrupted. Conversely, the fathers of older children may be loath to subject their families to the upheaval taking an academic job sometimes entails.

\section{Conclusion}

The path from graduate school to a tenure-track job is neither homogenous nor seamless. Although many people get ladder-rank positions right after graduate school, the majority do not. Of these, a noteworthy minority will find their way back to the tenure track. Thus the usual conception of academic careers as rigid pipelines is inappropriate (cf. Xie and Shauman 2003).

This article offers two general findings about the academic life course. First is the notion of staying in the game. Doctorates who are employed in academia - non-teaching positions and, especially, adjunct professorships - subsequently get tenure-track jobs at much higher rates than do those who leave it. We cannot know the extent to which this association is causal. Do people who fail to get ladder-rank professorships the first time around intentionally work in adjunct jobs in order to stay involved in academia? Or, are these jobs the natural second choice for otherwise unemployed doctorate recipients? Either way academic positions off the tenure track may facilitate 
reentry. They can provide teaching experience that fills out a curriculum vitae and increase one's attractiveness to academic hiring committees. Sometimes these jobs are parttime, which may give scholars the opportunity to conduct research (albeit without the institutional resources available to tenure-stream faculty). Finally, they may provide professional contacts and socialization. For all of these reasons, it may not be a professional death sentence for young doctorates to take adjunct teaching positions if they cannot land the coveted tenure-track professorship.

Our second finding concerns the intertwined roles played by gender and family formation in moving off and on the tenure track. Previous research has shown that women are over-represented in the ranks of adjunct instructors (Curtis 2004). Our study confirms that women are significantly more likely than men to become adjuncts right out of graduate school. Furthermore, we identify a key reason for this trend: family formation. Mothers with children under 6 are disproportionately likely to have adjunct professorships, but women without young children are employed in these positions at rates only slightly higher than are men. On the other hand, marriage cannot explain why women become adjuncts rather than tenure-stream faculty members. This casts doubt on a common stereotype of young academic couples, in which the husband gets the high status line appointment and his "trailing spouse" teaches parttime. The other common career move for mothers of young children is to stop working. Women with children under 6 are several times as likely as either men or other women to leave the labor force altogether. Marriage also plays a role here, with married women likely to be unemployed rather than in tenure-track professorships.

Young children not only push women off the tenure track, they keep them off. Women with children under 6 are disproportionately likely to remain off the tenure track. In contrast, older children substantially increase the chances of reentry. Together these findings suggest a new model of the academic life course. Some women leave the tenure track, customarily for adjunct professorships or non-employment, to raise children until they reach school age. Thereafter, they seek out full-time employment as ladderrank faculty members. Women who stay in the game by working as adjunct faculty members or, less frequently, in non-teaching academic jobs, are especially likely to return to the tenure track. Many will do so, although the longer women stay out the less likely they are to return. In any event, an adjunct position is a less-than-certain route to tenure-track employment.

If women with young children leave the tenure track and women with older children return to it, why aren't women with older children more likely to stay on right after graduate school? Few of these women probably exist. To have older children at the time of doctorate receipt means that childbirth occurred early in graduate school, if not before. We speculate that these are unlikely times for women to have children. (The SDR does 
not contain information on fertility prior to Ph.D. receipt.) Although we presume that many women at this stage eventually want children - after all, most Americans do (Thornton and Young-DeMarco 2001) - their lives may seem too unsettled to actually start having them.

Women Ph.D.s' interwoven patterns of family and career formation mirror those found in society more generally. Using data from the National Longitudinal Survey of Youth, Budig (2003) found that young children increase women's labor force exits, while older children decrease them. Moreover, women with preschool-age children are less likely to join the labor force in the first place. It makes sense that academic women may be adopting this model of family formation, although it works less well in academia than for other professions. Most non-academic women do not have the pressure of keeping their credentials "fresh" via ongoing research. Outside academia, gaps in one's employment history are perhaps more readily understood and accepted. More than most vocations, academia does not really offer any good time to have children. Our results suggest that female Ph.D.s may have responded by using adjunct professorships as an imperfect solution to structural problems intrinsic to the academic life course as we have come to know it.

Our findings show that the life course, with its focus on the sequencing of transitions, is a better conceptual tool for understanding women's academic careers than is the pipeline. For women, key professional transitions such as moving on and off the tenure track depend on personal transitions including family formation. Understanding the professional life course therefore requires insight into the family life course. Our findings regarding the interplay between family and career are mirrored by three more general trends in the life course (George 1993). First, disorder in the life course happens more now than it used to (Hogan 1978, 1981). This is clearly the case in academia: the ranks of adjunct faculty have swollen in recent years, with a stint as a part-time instructor prior to taking a tenuretrack job traditionally representing a non-normative academic career. Second, disorder in the life course happens more to women than men (Hogan 1985; Kirchoff 1990). This is also the case with our research, given the high rate at which women, especially those with young children, move into adjunct professorships. Third, and finally, disorder in the life course often produces adverse consequences (Hogan 1978; Rindfuss, Swicegood and Rosenfeld 1987). This idea is only partially supported by our research, in that many people who move off the tenure track are able to return.

Our results confirm that family formation causes difficulties for women at the beginning of their academic careers. What about later on? McElrath (1992) analyzed a sample of 250 social scientists and found that female scholars who spent time away from academia are less likely to get tenure. More recently, Wolfinger, Mason and Goulden (2008) used a 
national sample of more than 10,000 faculty members from all academic disciplines to show that family formation could not explain the lower rate at which women get tenure and promoted to full professor. This finding is supported by Donna Ginther's work, which suggests that measured respondent characteristics cannot account for why women still fare worse than men in securing tenure (Ginther 2001; Ginther and Hayes 2003; Ginther and Kahn 2004). Research on other professions indicates that time out of the labor force costs women economically (Noonan 2005; Noonan and Corcoran 2004), and there is no reason to believe academia is any different. Furthermore, time spent in adjunct professorships generally does not shorten the years spent as an untenured assistant professor.

In The Structure of Social Action, Talcott Parsons (1968 [1937]) draws a distinction between normative order (what should happen) and factual order (what does happen). In academia, the two traditionally coincided: young male scholars received their Ph.D.s, perhaps spent a year or two in postdoctoral fellowships, then moved seamlessly into tenure-track positions. But increasingly there is discrepancy between the normative order and the factual order of the academic life course. More women are receiving Ph.D.s, yet academia does not offer them any good time to have children. As a result, women may have developed a new response to structural problems inherent to the academic life course. In other words, a new factual order is developing in response to work-family conflict in academia. Barring dramatic shifts in the system of academic careers, spending time in adjunct positions may become the new normative order for women desiring both families and professorships. Given the low wages, low status and lack of job security that characterize these positions, this is not an optimal solution to the difficulties women face in combining families and academic careers.

The proliferation of adjunct teaching positions, echoing the society-wide shift to contingent labor (cf. Barker and Christensen 1998), can provide a means - albeit uncertain - for women to work their way back to the tenure track. This ad hoc solution illustrates the need for a new normative order for the academic life course to augment the traditional, male-oriented model of academic careers. Possibilities here include more part-time tenure-track positions and adjunct positions with longer contracts (WolfWendel et al. 2003), as well as "reentry" post-doctoral fellowships - "onramps," in the language of Hewitt and Luce (2005) - designed to ease new parents back into academia. Our findings also raise more general questions about work-family tensions outside academia. Adjunct positions are a structural feature of the academic workplace that can serve specific functions in allowing academic women to stay in the game. Future studies should consider the ad hoc arrangements pursued by women in fast-track professions besides academia. 


\section{Notes}

1. Throughout this article we use the expression adjunct faculty as shorthand for all college instructors who are not tenured or tenure track. These instructors have numerous titles; conversely, some tenure-track faculty also hold adjunct appointments.

2. Levels of full-time employment by adjuncts are likely to be under-reported. Sometimes faculty members are classified by their institutions as "parttime," even though they teach four or five courses per term. This occurs because adjuncts split their teaching among two or more institutions of higher learning (AAUP 2003).

3. We refer to movement into ladder-rank positions down the road from Ph.D. receipt as returns to the tenure track, reflecting the notion of a normative pathway between the completion of graduate school and the commencement of a tenure-track assistant professorship; this pathway comprises the track that traditionally leads to tenure.

4. The SDR does not contain adequate data on career intentions. About half of new Ph.D.s plan to remain in academia (Sanderson and Dugoni 1999); this statistic does not distinguish between tenure-track professorships, adjunct positions and other assignations in higher education.

5. In additional analyses, not shown, we explore whether the relationship between employment status and having a tenure-track job has changed over time. The results indicate a positive and statistically significant interaction between having an adjunct position and Ph.D. calendar year. In other words, adjuncts have reentered the tenure track at disproportionately higher rates in recent years.

\section{References}

Allison, Paul D. 1995. Survival Analysis using the SAS System: A Practical Guide. Cary, NC: SAS Institute, Inc.

Allison, Paul D., and J. Scott Long. 1987. "Interuniversity Mobility of Academic Scientists." American Sociological Review 52(5):643-52.

American Association of University Professors. 2003. "Policy Statement: Contingent Appointments and the Academic Profession." Available at: http:// www.aaup.org/statements/SpchState/Statements/contingent.htm.

2005. "Background Facts on Contingent Faculty." Available at: http:// www.aaup.org/lssues/part-time/Ptfacts.htm.

2008. "Trends in Faculty Status, 1975-2005." Available at: http://www. aaup.org/NR/rdonlyres/9218E731-A68E-4E98-A378-12251FFD3802/0/ Facstatustrend7505.pdf. 
Astin, Helen, and Jeffrey F. Milem. 1997. "The Status of Academic Couples in U.S. Institutions." Pp. 128-55. Academic Couples: Problems and Promises. M.A. Ferber and J.W. Loeb, editors. University of Illinois Press.

Barker, Kathleen, and Kathleen Christensen. Editors. 1998. Contingent Work: American Employment Relations in Transition. Cornell University Press.

Bassett, Rachel Hile. Editor. 2005. Parenting and Professing: Balancing Family Work with an Academic Career. Vanderbilt University Press.

Benjamin, Ernst. 2002. "How Over Reliance on Contingent Appointments Diminishes Faculty Involvement in Student Learning." Peer Review 4(2):4-10.

Budig, Michelle J. 2003. "Are Women's Employment and Fertility Histories Interdependent? An Examination of Causal Order Using Event History Analysis." Social Science Research 32(3):376-401.

California Birth Defects Monitoring Program. 2005. Registry Data, 1997-2001. Available at: http://www.cbdmp.org/bd_down_syn.htm.

Carr, Phyllis L., Laura Szalacha, Rosalind Barnett, Cheryl Caswell and Thomas Inui. 2003. "A 'Ton of Feathers': Gender Discrimination in Academic Medical Careers and How to Manage It." Journal of Woman's Health 12(10):1009-18.

Clausen, John S. 1991. "Adolescent Competence and the Shaping of the Life Course." American Journal of Sociology 96(4):805-42.

Cobb III, Curtiss L., and Jon Krosnick. 2007. "The Effects of Postdoctoral Appointments on Career Outcomes and Job Satisfaction." Paper presented at the Using Human Resource Data from Science Resources Statistics Workshop, National Science Foundation, Arlington, VA, on Oct. 12.

Conley, Valerie Martin, David W. Leslie and Linda J. Zimbler. 2002. "Part-Time Instructional Faculty and Staff: Who They Are, What They Do, and What They Think." Washington, DC: U.S. Department of Education, National Center for Education Statistics, NCES. Available at: http://nces.ed.gov/pubsearch/ pubsinfo. asp? pubid $=2002163$.

Correll, Shelley J., Stephen Benard and In Paik. 2007. "Getting a Job: Is There a Motherhood Penalty?" American Journal of Sociology 112(5):1297-338.

Curtis, John W. 2004. "Faculty Salary and Faculty Distribution Fact Sheet 2003-04." American Association of University Professors. Available at: http://www.aaup. org/AAUP/pubsres/research/2003-04factsheet.htm.

. 2005. "Inequities Persist for Women and Non-Tenure-Track Faculty." Academe 91(2):21-30.

Dubson, Michael. Editor. 2001. Ghosts in the Classroom: Stories of College Adjunct Faculty - and the Price We All Pay. Camel's Back Books. 
Fountain, Wendell V. 2005. Academic Sharecroppers: Exploitation of Adjunct Faculty and the Higher Education System. Authorhouse.

Elder Jr., Glen H. 1994. "Time, Human Agency, and Social Change: Perspectives on the Life Course." Social Psychology Quarterly 57(1):4-15.

. 1999. Children of the Great Depression, 25th Anniversary Edition. Westview Press.

2002. "The Life Course and Aging: Some Accomplishments, Unfinished Tasks, and New Directions." Paper presented at the annual meeting of the Gerontological Society of America, Boston, on Nov. 11.

Elder Jr., Glen E., and Angela M. O'Rand. 1995. "Adult Lives in a Changing Society." Pp. 452-75. Sociological Perspectives in Social Psychology. K.S. Cook, G.A. Fine and J.S. House, editors. Simon and Schuster.

Gatta, Mary L., and Patricia A. Roos. 2002. "Balancing without a Net in Academia: Integrating Family and Work Lives." Unpublished paper. Rutgers University: Center for Women and Work.

George, Linda K. 1993. "Sociological Perspectives on Life Transitions." Annual Review of Sociology 19:353-73.

Ginther, Donna K. 2001. "Does Science Discriminate Against Women? Evidence from Academia, 1973-97." Federal Reserve Bank of Atlanta, Working Paper 2001-2. Available at: http://www.frbatlanta.org/filelegacydocs/wp0102.pdf.

Ginther, Donna K., and Kathy J. Hayes. 2003. "Gender Differences in Salary and Promotion for Faculty in the Humanities" Journal of Human Resources $38(1): 34-73$.

Ginther, Donna K., and Shulamit Kahn. 2004. "Women in Economics: Moving up or Falling off the Academic Ladder?" Journal of Economic Perspectives 18(3): 193-214.

Hewlett, Sylvia Ann, and Carolyn Buck Luce. 2005. "Off-Ramps and On-Ramps: Keeping Talented Women on the Road to Success." Harvard Business Review 83(3):43-54.

Hoffer, Thomas B., Bernard L. Dugoni, Allen R. Sanderson, Scott Sederstrom, Rashna Ghadialy and Peter Rocque. 2001. Doctorate Recipients from United States Universities: Summary Report 2000. Chicago: National Opinion Research Center.

Hogan, Dennis P. 1978. "The Variable Order of Events in the Life Course. "American Sociological Review 43(4):573-86.

. 1981. Transitions and Social Change: The Early Lives of American Men. Academic Press. 
1985. "The Demography of Life-Span Transitions: Temporal and Gender Comparisons." Pp. 65-78. Gender in the Life Course. A. Rossi, editor. Aldine de Gruyter.

Jacobs, Jerry A. 1989. Revolving Doors: Sex Segregation and Women's Careers. Stanford University Press.

. 1996. "Gender Inequality and Higher Education." Annual Review of Sociology 22:153-85.

2004. "The Faculty Time Divide." Sociological Forum 19(1):3-27.

Jacobs, Jerry A., and Sarah E. Winslow. 2004a. "Overworked Faculty: Job Stresses and Family Demands." The Annals of the American Academy of Political and Social Science 596(1):104-29.

2004b. "The Academic Life Course, Time Pressures, and Gender Inequality." Community, Work, and Family 7(2):143-61.

Kerckhoff, Alan C. 1990. Getting Started: Transition to Adulthood in Great Britain. Westview Press.

Kulis, Stephen, and Dianne Sicotte. 2002. "Women Scientists in Academia: Geographically Constrained to Big Cities, College Clusters, or the Coasts?" Research in Higher Education 43(1):1-30.

Kulis, Stephen, Dianne Sicotte and Shawn Collins. 2002. "More Than a Pipeline Problem: Labor Supply Constraints and Gender Stratification across Academic Science Disciplines." Research in Higher Education 43(6):657-91.

Long, J. Scott. 2001. From Scarcity to Visibility: Gender Differences in the Careers of Doctoral Scientists and Engineers. National Academy Press.

Mason, Mary Ann, and Marc Goulden. 2004. "Marriage and Baby Blues: Redefining Gender Equity in the Academy." The Annals of the American Academy of Political and Social Science 596(1):86-103.

Mason, Mary Ann, Marc Goulden and Nicholas H. Wolfinger. 2006. “Babies Matter: Pushing the Gender Equity Revolution Forward." Pp. 9-30. The Balancing Act: Gendered Perspectives in Faculty Roles and Work Lives. S.J. Bracken et al., editors. Stylus.

Massachusetts Institute of Technology. 1999. "Special Edition: A Study on the Status of Women Faculty in Science at MIT." The MIT Faculty Newsletter 11(4). Available at: http://web.mit.edu/fnl/women/women.html\#The\%20Study.

McElrath, Karen. 1992. "Gender, Career Disruption, and Academic Rewards." The Journal of Higher Education 63(3):269-81.

Moen, Phyllis. 2003. It's About Time: Couples and Careers. Cornell University Press. 
Monks, James. 2004. "Public versus Private University Presidents Pay Levels and Structure." Cornell Higher Education Research Institute, Working Paper 58. Available at: http://digitalcommons.ilr.cornell.edu/cheri/21.

National Center for Education Statistics. 2001. The Integrated Postsecondary Education Data System Salaries, Tenure, and Fringe Benefits of Full-Time Instructional Faculty Survey. Washington, DC: NCES.

National Science Foundation. 1995. "Changes to the Survey of Doctorate Recipients in 1991 and 1993: Implications for Data Users." Website: www.nsf.gov.

2003. "Survey of Doctorate Recipients." Available at: http://www.nsf.gov/ statistics/srvydoctoratework.

The New York Times. 2005. "Rift Deepens as Professors at Harvard See Remarks." February 19. Available at: http://www.nytimes.com/2005/02/19/ education/19harvard.html? $r=1 \& s c p=172 \& s q=$ february $\% 2019, \% 20$ 20058st $=$ cse.

Noonan, Mary C. Forthcoming. "The Long-Term Costs of Women's Work Interruptions." Unpublished Paper, Department of Sociology, University of lowa.

Noonan, Mary C., and Mary E. Corcoran. 2004. "The Mommy Track and Partnership: Temporary Delay or Dead End?" Annals of the American Academy of Political and Social Science 596(1):130-50.

O'Laughlin, Elizabeth M., and Lisa G. Bischoff. 2005. "Balancing Parenthood and Academia: Work/Family Stress as Influenced by Gender and Tenure Status." Journal of Family Issues 26(1):79-106.

Paul, Christopher, William M. Mason, Daniel McCaffrey and Sarah A. Fox. 2008. "A Cautionary Case Study of Approaches to the Treatment of Missing Data." Statistical Methods and Applications 17(3):351-72.

Parsons, Talcott. 1968[1937]. The Structure of Social Action. The Free Press.

Perna, Laura W. 2001. "The Relationship between Family Responsibilities and Employment Status among College and University Faculty." The Journal of Higher Education 72(5):584-611.

Powers, Daniel A., and Yu Xie. 2000. Statistical Methods for Categorical Data. Academic Press.

Rindfuss, Ronald C., C. Gray Swicegood and Rachel A. Rosenfeld. 1987. "Disorder in the Life Course: How Common and Does It Matter?" American Sociological Review 52(6):785-801.

Roos, Patricia A., and Katharine W. Jones. 1995. "Shifting Gender Boundaries: Women's Inroads into Academic Sociology." Pp. 297-333. Gender Inequality at Work. J.A. Jacobs, editor. Sage. 
Sanderson, Allen R., and Bernard Dugoni. 1999. Summary Report 1997: Doctorate Recipients from United States Universities. Chicago: National Opinion Research Center.

Suitor, J. Jill, Dorothy Mecom and Ilana S. Feld. 2001. "Gender, Household Labor, and Scholarly Productivity Among University Professors." Gender Issues 19(4):50-67.

Summers, Lawrence H. 2005. Remarks at National Bureau of Economic Research Conference on Diversifying the Science \& Engineering Workforce, Harvard University. Jan. 14. Available at: http://www.president.harvard.edu/ speeches/2005/nber.html.

Thornton, Arland, and Linda Young-DeMarco. 2001. "Four Decades of Trends in Attitudes Toward Family Issues in the United States: The 1960s Through the 1990s." Journal of Marriage and Family 63(3):1009-37.

Valian, Virginia. 1998. Why So Slow?: The Advancement of Women. MIT Press.

Van Anders, Sari M. 2004. "Why the Academic Pipeline Leaks: Fewer Men than Women Perceive Barriers to Becoming Professors." Sex Roles 51(9-10):511-21.

West, Martha S. 1994. "Gender Bias in Academic Robes: The Law's Failure to Protect Women Faculty." Temple Law Review 67(68):67-178.

Widnall, Shiela E. 1988. "AAAS Presidential Lecture: Voices from the Pipeline." Science 241(4874): 1740-45.

Winship. Christopher, and Larry Radbill. 1994. "Sampling Weights and Regression Analysis." Sociological Methodology and Research 23(2):230-57.

Wolfinger, Nicholas H., Mary Ann Mason and Marc Goulden. 2008. "Problems in the Pipeline: Gender, Marriage, and Fertility in the Ivory Tower." The Journal of Higher Education 79(4):388-405.

Wolf-Wendel, Lisa, Susan B. Twombly and Suzanne Rice. 2003. The Two-Body Problem: Dual-Career-Couple Hiring Practices in Higher Education. Johns Hopkins University Press.

Xie, Yu, and Kimberlee A. Shauman. 1998. "Sex Differences in Research Productivity: New Evidence about an Old Puzzle." American Sociological Review 63(6):847-70.

2003. Women in Science: Career Processes and Outcomes. Harvard University Press. 
Appendix. Summary Statistics

\begin{tabular}{lc}
\hline Female & $34 \%$ \\
Child < 6 & $28 \%$ \\
Child 6-17 & $18 \%$ \\
Married & $67 \%$ \\
Field & \\
Bench sciences & $60 \%$ \\
Social sciences & 25 \\
Humanities & 15 \\
Race & \\
White & $79 \%$ \\
Black & 2 \\
Asian-American & 14 \\
Latino & 3 \\
Other/unknown & 2 \\
Rank of Graduate Program & \\
Best quartile & $62 \%$ \\
2nd quartile & 22 \\
3rd quartile & 14 \\
Worst quartile & 10 \\
Program unranked & $9 \%$ \\
Field unranked & $7 \%$ \\
Time to Degree & \\
Fastest quartile & $17 \%$ \\
2nd quartile & 23 \\
3rd quartile & 28 \\
Slowest quartile & 30 \\
Data missing & $2 \%$ \\
Had Post-doctoral Fellowship & $11 \%$ \\
Age at Ph.D. & 35 \\
Ph.D. Calendar Year & 1989 \\
Time Since Ph.D. & 1 \\
First Post-doctoral Position & $(3.27)$ \\
Tenure-track position & $35 \%$ \\
Adjunct professorship & 9 \\
Non-teaching academic & 6 \\
Non-university employment & 45 \\
Out of paid labor force & 5 \\
\hline & \\
\hline
\end{tabular}

Notes: Numbers in parentheses are standard errors. Percentages may not sum to 100 due to rounding error.

$\mathrm{N}=16,049$ 
1622 - Social Forces 87(3) 